ISSN: $2594-4827$

\title{
EDUCAÇÃO FÍSICA, ESCOLA UNITÁRIA E CURRÍCULO INTEGRADO: POSSIBILIDADES NA EDUCAÇÃO PROFISSIONAL E TECNOLÓGICA ${ }^{1}$
}

\author{
Fabrício Gurkewicz Ferreira ${ }^{2}$ \\ Júlia de Sousa Lopes Basso ${ }^{3}$
}

\section{RESUMO}

O presente trabalho é o resultado de análises da relação existente entre Escola Unitária, Educação Física e Currículo Integrado bem como as suas possibilidades na Educação Profissional e Tecnológica. Para o percurso metodológico fez-se a pesquisa bibliográfica. Como resultado de nossas análises verificamos que a disciplina de Educação Física, no âmbito da Educação Profissional e Tecnológica, pode contribuir para formação integral dos sujeitos desde que subsidiada pela orientação de um Currículo Integrado. Para tanto, essa matriz curricular deve viabilizar a integração dos saberes em suas distintas dimensões, além de abarcar princípios que considerem os conteúdos de reconhecida relevância e que favoreçam o diálogo com a bagagem da cultura corporal que o aluno já traz consigo.

Palavras-chave: Escola unitária; Educação física; Currículo integrado; Educação profissional e tecnológica.

\begin{abstract}
The present workis a result of relationshipanalyzes there are between the Unitary School, Physical Education and Integrated Curriculum as well as its possibilities in Professional and Technological Education. For the methodological design, we used the bibliographic research review. As a result of our studies, we verified that the Physical Education discipline in the scope of Professional and Technological Education can contribute to the integral formation of the subjects since it is subsidized by the orientation of an Integrated Curriculum. In order to do so, this curriculum matrix should enable the integration of knowledge in different dimensions, as well as encompass principles that consider contents of recognized relevance and that favor dialogue with the baggage of body culture that the student already brings with him.
\end{abstract}

Key-words: Unitary school; Physical education; Integrated curriculum; Professional and technological education.

\footnotetext{
${ }^{1}$ Uma versão preliminar desse texto foi apresentada no I Simpósio Amazônico em Educação Profissional e Tecnológica, promovido pelo ProfEPT/IFAM/CMC, realizado em Manaus, Amazonas, nos dias 28 a 29/11/2018.

${ }^{2}$ Estudante do Mestrado Profissional em Educação Profissional e Tecnológica do Instituto Federal de Educação, Ciência e Tecnologia de Rondônia - Campus Calama, fabricio.gurkewicz@ifro.edu.br

${ }^{3}$ Estudante do Mestrado Profissional em Educação Profissional e Tecnológica do Instituto Federal de Educação, Ciência e Tecnologia de Rondônia - Campus Calama, julia.basso@ plc.ifmt.edu.br
} 
ISSN: 2594-4827

\section{INTRODUÇÃO}

O presente trabalho está vinculado aos estudos e discussões ocorridos na disciplina de "Bases conceituais para a educação profissional e tecnológica", do Mestrado Profissional em Educação Profissional e Tecnológica 2018, realizado no Instituto Federal de Rondônia - Campus Calama. Investigamos aqui os conceitos e as suas implicações na sociedade moderna, da Escola Unitária, proposição educacional elaborada pelo filósofo italiano Antônio Gramsci, que viveu nas primeiras décadas do século passado. Como nossa formação inicial e atuação profissional é na área de Educação Física, ao realizarmos a imersão nos postulados gramscianosreferentes a educação, em especial a Educação Profissional e Tenológica, indagações começaram a surgir a respeito de uma possível articulação entre a nossa área, Educação Física, e a Escola Unitária, no sentido da efetivação do Curriculo Integrado.

A Escola Unitária, proposição idealizada por Gramsci durante o seu periodo no cárcere,é o meio enxergado pelo filósofo italiano, para que as camadas populares tenham as mesmas oportunidades de formação ofertadas as classe dominantes, tendo, posteriormente, a possibilidade de alcançar a função de dirigente, no meio social. É uma proposta de inspiração marxista, que está voltada para a sociedade capitalista italiana do inicio do século XX. No cerne da sua proposição, está a necessidade de um processo formativo que atue em uma perspectiva integral, contemplando todas as dimensões do ser.

Para alcançar esse objetivo, é necessária a participação de várias áreas do conhecimento, dentre elas a Educação Física. Essa área é responsável por abranger os conhecimentos relacionados as práticas corporais, que são oriundos de diversos ambientes sócio-culturais, em diferentes momentos históricos. No entanto, ao longo de sua história no contexto educacional brasileiro, sempre esteve vinculada aos interesses das classes dominantes, reproduzindo as relações de poder da estrutura social, que podem ser obervados por meio da predominância de certos conteúdos, como o esporte, em detrimento dos demais.

$\mathrm{Na}$ tentativa de colaborar, de fato, com a formação integral, a Educação Física, assim como os demais componentes curriculares, demandam uma estrutura curricular 
que os norteie de forma adequada. Esse papel pode ser exercido pelo CurriculoIntegrado, que é uma forma de organização na qual se procura a integração dos saberes, tendo como eixos o trabalho, a ciência, a cultura e a tecnologia. A sua implantação no ambiente educacional significa a possibilidade de superação da fragmentação na apropriação do conhecimento e a formação de um sujeito por inteiro.

Desse modo, apesar deserem áreas distantes uma das outras, podemos perceber pontos em comum, que aproximam a Escola Unitária, a Educação Física e o Currículo Integrado. Esperamos, com este estudo, constituir alguns apontamentos que demonstrem as possibilidades dessa relação e as suas implicações na Educação Profissional e Tecnológica.

\section{METODOLOGIA}

Esse estudo tem como referência metodológica a pesquisa bibliográfica. Esse método se caracteriza pela utilização de materiais já elaborados, como artigos científicos e livros, na construção do trabalho. Apesar de muitos estudos demandarem ações dessa natureza, há pesquisas que se estruturam exclusivamente por meio de fontes bibliográficas. Dentre as vantagens desse método, temos a possibilidade do pesquisador abranger uma quantidade maior de fenômenos, sem ter que estar envolvido em todos eles (GIL, 2002).

Para a concretização do nosso percurso investigativo, inicialmente delimitamos os termos a serem problematizados. A partir dos estudos em uma disciplina do programa de mestrado, aprofundamos os nossos conhecimentos a respeito da Escola Unitária de Gramsci. Posteriormente, em meio a muitas reflexões, constatamos que seria interessante verificar de que modo essa categoria significativa do âmbito educacional pode se relacionar com a nossa disciplina de atuação profissional, a Educação Física. Por fim, após mais reflexões e leituras, percebemos que no campo da organização curricular, essa relação pode acontecer de forma profícua, e concentramos os nossos esforços em analisar de que modo esse processo se constitui. 
ISSN: $2594-4827$

\section{DISCUSSÃO}

A educação, assim como outras instituiçõospresentes na sociedade, reproduz os mecanismos existentes no cerne da estrutura social. No caso da sociedade capitalista, é o pensamento dual. Especificamente no campo da educação, observa-se a divisão entre aquela destinada aos que produzem a vida e a riqueza da sociedade usando sua força de trabalho e aquela destinada aos dirigentes, às elites, aos grupos e segmentos que dão orientação e direção à sociedade. A solução para acabar com essa dicotomia educacional, segundo Gramsci, seria a adoção de "uma Escola Única, destinada a todos os alunos e que propiciasse uma cultura geral, humanista, formativa, que equilibre o desenvolvimento da capacidade de trabalhar manualmente (tecnicamente, industrialmente) e o desenvolvimento das capacidades de trabalho intelectual" (GRAMSCI, 2000, p.118).

De acordo com Ramos (2008) a educação unitária pressupõe que todos tenham acesso aos conhecimentos, à cultura e às mediações necessárias para trabalhar e para produzir a existência e a riqueza social. A adoção de uma Escola Única seria a solução para acabar com a dicotomia educacional e deveria ser destinada a todos os alunos. Ela deverá apresentar as seguintes características: ser totalmente financiada pelo governo, o período da educação básica deverá ser por volta de dez anos, a infraestrutura deverá possibilitar o desenvolvimento de todas as atividades educacionais, a quantidade de docentes deverá ser ampla, a sua organização em um período integral e deverá criar condições voltadas para a autonomia do estudante somente em sua parte final (GRAMSCI, 2000).

Como finalidade, percebemos então, que ela busca abranger o seu duplo sentido, o de ser uma escola única, comum que seja ofertada a todas as pessoas e que concretize a articulação entre a dimensão cultural e à prática. E espera-se, também, que ocorra a propagação do princípio unitário em todas as instâncias da vida social, promovendo a sua transformação. Ainda podemos ressaltar, a sua estreita relação com o sentido da formação humana na aprendizagem para o trabalho, por meio do entendimento deste como princípio educativo.

Gramsci retoma o entendimento do trabalho sob o viés ontológico, “ao considerar o 'ser' a partir de sua incessante busca por satisfazer suas necessidades imediatas e 
humanas, encontrando no processo de trabalho a única forma de humanizar-se, de sobreviver às intempéries da natureza e dominá-la" (GRAMSCI apud RIBEIRO, SOBRAL E JATAÍ, 2016, p.276). Nesse mesmo sentido, Ramos (2008) vê o trabalho como realização humana, visto que o trabalho medeia os conhecimentos produzidos pela humanidade, tornando-os legitimados socialmente como conhecimentos válidos, explicando a realidade e possibilitando a intervenção sobre ela.

Ao refletirmos sobre os postulados Gramscianos apresentados até aqui, observamos a ênfase na formação humana e o trabalho como princípio educativo mediando essas relações, uma vez que as suas ideias tem influência Marxista. Os sistemas de ensino, portanto, devem direcionar as suas ações visando a contemplação desses aspectos. Ao aprofundarmos essa questão, chegando ao campo das disciplinas, verificamos que a Educação Física na Educação Profissional e Tecnológica, pode contribuir nesse processo, já que ela se confunde com o ser humano desde o momento em que o homem se diferenciou dos animais e passou a agir na ambiente em que estava inserido, adaptando-o às suas necessidades. Assim, as suas possibilidades são significativas contanto que abordadas no sentido ontológico.

Essa disciplina, produto de práticas sociais, possibilita ao homem tornar-se um ser social, desde que concebida como um meio de expressividade e constituída dos elementos da cultura corporal. Desse modo, ela poderá promover à práxis defendida por Gramsci, que é a atividade sensível humana pensada, analisada e voltada para a transformação social, por meio dos momentos de interação com o outro, em que discussões e negociações se fazem presente, demonstrando as diferenças e limitações presentes no grupo, que fazem emergir soluções construídas mediante o trabalho coletivo e solidário (ANVERSA; SOUZA, 2016).

Nesse sentido, a Educação Física precisa ir além do movimento técnico. Isto significa que deverá ocorrer o reconhecimento da sua importância, mas não ficar restrito a ele. Esse processo de conhecimento será o primeiro passo para que seja viabilizado a criação, recriação e transformação do seu gestual, "fomentando a formação humana, recriações e reinterpretações do movimento levando a superação, isto porque, promove a separação de estrutura e superestrutura, pois uma e outra não existem fora da história e do seu desenvolvimento[...]" (ANVERSA; SOUZA, 2016, p. 156). 
As ações pedagógicas da área devem estar alicerçadas sobre princípios e saberes históricos que considerem o homem como sujeito determinado e determinante da sua história, ou seja, embora condicionado no seu processo de formação, ele pode e deve se portar de forma ativa para que consiga romper com a hegemonia imposta e buscar novos meios de atuação. Para tanto, é imprescindível delimitar uma estrutura curricular que vá ao encontro desses pressupostos e que possibilite, no âmbito da Educação Profissional e Tecnológica, uma formação humana.

A Educação Física sempre esteve, historicamente, alinhada aos interesses da classe que estava no poder, concorrendo para a manutenção da estrutura capitalista. Nos primórdios de sua implantação no Brasil, estava ligada ao pensamento higienista e eugenista da sociedade europeia, em que o objetivo era construção de um corpo saudável, vigoroso, disciplinado, pronto para atender as demandas sociais. Posteriormente, capitaneada pela hegemonia do esporte na escola, compromete-se com os princípios de racionalidade, eficiência e rendimento, elementos essenciais em uma sociedade controlada pelo capital.

Por essa breve contextualização, constatamos que a disciplina sempre foi condicionada para servir a interesses específicos. As práticas, ao longo das mudanças sócio-históricas brasileiras, sempre tiveram o objetivo de desenvolver a aptidão física dos educandos. Esse viés ainda predomina na grande maioria das aulas vigentes na educação básica, embora, atualmente, a maior parte dos documentos curriculares estejam estruturados sob uma perspectiva cultural.

O currículo orientado para a aptidão física se fundamenta, principalmente, nos fatores biológicos visando à formação de um homem forte, capaz, empreendedor, que lute para conquistar um espaço privilegiado em uma sociedade competitiva, que "oferece" as mesmas condições a todos: a capitalista. Ao perfazer esse tipo de educação, intenta a adaptação do homem à realidade, alienando-o de sua condição de sujeito histórico, impossibilitando a sua intervenção na mesma. Também recorre à filosofia liberal, para que na consolidação do processo formativo, esteja contemplada a obediência e um comportamento conformado e padronizado (COLETIVO DE AUTORES, 1992). 
Contudo, considerando que a Educação Física é a área do conhecimento que se propõe a refletir sobre a gama de conhecimentos produzidos ao longo da história pelo homem por meio da expressão corporal, a dinâmica curricular deverá ser diferente. O objeto de estudo da disciplina, aqui denominado Cultura Corporal, abrange diversos temas, tais como a ginástica, o esporte, as lutas, as danças, dentre outros (COLETIVO DE AUTORES, 1992).

As contribuições da Educação Física na Educação Profissional e Tecnológica para o pleno exercício da cidadania é ampliada quando relacionada a concepção de cultura corporal, pois, desenvolvendo como produtos socioculturais os seus conteúdos e suas capacidades, torna-os acessíveis a todos, e, por conseguinte adota uma perspectiva metodológica de ensino e aprendizagem que busca o desenvolvimento da autonomia, a cooperação, a participação social e a afirmação de valores e princípios democráticos (BRASIL, 1997).

Os Parâmetros Curriculares Nacionais (1997) enfatizam que a disciplina de Educação Física se aprofunda em debates e discussões importantes sobre aspectos éticos e sociais e permite ver que as diferentes práticas corporais, advindas das mais diversas manifestações culturais, estão presentes na vida cotidiana. Ademais, esse conhecimento contribui para a adoção de uma postura não discriminatória e preconceituosa frente às manifestações e expressões dos diferentes grupos étnicos e sociais e às pessoas que dele fazem parte.

Junto ao desenvolvimento de práticas corporais, estão relacionados os conhecimentos sobre o corpo, seu processo de crescimento e desenvolvimento, dando subsídio para bons hábitos como: alimentação saudável, higiene e atividade corporal e para o desenvolvimento das potencialidades corporais do indivíduo (BRASIL, 1997).

Desta forma, no âmbito da Educação Física na Educação Profissional e Tecnológica, os conhecimentos construídos devem possibilitar a análise crítica dos valores sociais, tais como os padrões de beleza e saúde; ética do esporte profissional; discriminação sexual e racial; estética do ponto de vista do bem-estar; as posturas não consumistas, não preconceituosas, não-discriminatórias e a consciência dos valores coerentes com a ética democrática, entre outros (BRASIL, 1997). 
A partir desses entendimentos, constatamos que a prática da Educação Física na Educação Profissional e Tecnológica, poderá favorecer a autonomia dos alunos para monitorar as próprias atividades, regulando o esforço, traçando metas, conhecendo as potencialidades e limitações e sabendo distinguir situações de trabalho corporal que podem ser prejudiciais. Ela contribuirá, desse modo, para a uma formação humana em um sentido mais completo, como apontado por Gramsci em seus postulados, propiciando aos sujeitos uma leitura e atuação critica na realidade.

Nessa perspectiva, o currículo tem papel fundamental para que se efetivem essas proposições. Ele é concebido como um instrumento, que tem por função social, estruturar a reflexão pedagógica do aluno de modo que ele compreenda a realidade social por meio da construção de uma determinada lógica. Esse processo é concretizado por intermédio da apropriação do conhecimento cientifico, articulando-o ao saber que o aluno traz consigo e de outras referências do pensamento humano, tais como, a ideologia, as relações sociais, dentre outras (COLETIVO DE AUTORES, 1992).

Essa composição curricular vai além daquela que objetiva apenas contemplar parte da produção sociocultural humana. Ela tenciona a constatação, interpretação, compreensão e explicação da realidade social complexa e contraditória, tendo em vista o seu comprometimento com os interesses das camadas populares. O Coletivo de Autores (1992) indica alguns princípios para materializar uma proposta nessa perspectiva, quais sejam, relevância social do conteúdo, contemporaneidade, adequação as possibilidades sócio cognoscitivas do aluno, simultaneidade e provisoriedade dos conhecimentos.

A relevância social do conteúdo está relacionado com os sentidos e significados que o conteúdo deverá implicar na reflexão pedagógica escolar. A sua origem está estritamente vinculada com a produção cultural universal e, por conseguinte, a sua importância deve estar em constante avaliação. Assim, ele deverá "estar vinculado à explicação da realidade social concreta e oferecer subsídios para a compreensão dos determinantes sócio históricos do aluno, particularmente a sua condição de classe social" (COLETIVO DE AUTORES,1992, p.19).

A contemporaneidade se refere à necessidade de que os conteúdos a serem ofertados aos alunos assegurem os conhecimentos do que de mais moderno exista no 
mundo contemporâneo, informando-os dos acontecimentos que ocorram tanto na esfera nacional quanto na internacional, além daquilo que envolva a técnica e a ciência. Isso não quer dizer que os conteúdos clássicos serão descartados, pois eles são compreendidos como saberes fundamentais. Desse modo, os conteúdos contemporâneos também são clássicos (COLETIVO DE AUTORES, 1992).

A adequação às possibilidades sócio cognoscitivas do aluno diz respeito a se levar em conta, no momento de seleção do conteúdo, aqueles que sejam condizentes com a capacidade cognoscitiva e à prática social do aluno, ao conhecimento que ele possui no momento e a sua condição como sujeito histórico (COLETIVO DE AUTORES, 1992). Devem-se propor conhecimentos, os quais os alunos tenham condição de assimilar e atuar na sua reelaboração. Para tanto, uma metodologia adequada, que considere cada aluno como um sujeito único, é essencial.

A simultaneidade envolve a necessidade dos conteúdos serem organizados e apresentados de forma simultânea. Sob essa ótica, há uma superação da divisão dos conteúdos distribuídos por etapa, na qual os conhecimentos são ordenados por meio do estabelecimento do seu nível de complexidade e que pode ser vista nas instituições que arranjam os seus alunos por série, por uma que explicita a relação que os conhecimentos possuem entre si e com o todo. Nesse sentido, colabora para a superação de uma realidade mecanicista, fragmentária (COLETIVO DE AUTORES, 1992).

A provisoriedade dos conhecimentos se opõe a ideia de terminalidade do conhecimento. Relaciona-se com o fato de os conhecimentos serem frutos de um momento histórico especifico e, independente da natureza da produção humana, seja intelectual, científica, moral, etc, revela um determinado estágio da humanidade que, não necessariamente, ocorrerá em outros períodos. Para a sua efetivação, é fundamental "[...] apresentar o conteúdo ao aluno, desenvolvendo a noção de historicidade, retraçando-o desde a sua gênese, para que este aluno se perceba enquanto sujeito histórico."(COLETIVO DE AUTORES,1992, p. 21).

Com a utilização desses princípios, pode-se estabelecer um arranjo curricular no campo da Educação Física e das demais disciplinas, para que se efetue uma formação humana que promova o amplo desenvolvimento das capacidades dos sujeitos. No entanto, a atual conjuntura educacional, demanda uma estrutura curricular que viabilize 
a integração das áreas do conhecimento, para que o processo formativo seja ainda mais significativo. Nesse sentido, Araújo e Frigotto (2015) nos apresentam alguns princípios que visam ao rompimento com a visão linear e compartimentada dos conteúdos, consubstanciando um Currículo Integrado. São eles: a contextualização, a interdisciplinaridade e o compromisso com a transformação social.

A contextualização é a articulação entre os conteúdos trabalhados com a realidade social e os projetos políticos dos trabalhadores e de suas organizações sociais. A interdisciplinaridade visa a exploração das potencialidades de cada disciplina, construindo aproximações, mas respeitando as suas peculiaridades. $\mathrm{O}$ compromisso com a transformação social demonstra a teleologia da proposta e lhe distingue de outros projetos que buscam a integração dos conhecimentos, mas que são estéreos, pois concorrem para a conformação social (ARAÚJO; FRIGOTTO, 2015).

Para Ramos (2008) a construção de um currículo integrado envolve a presença de dois pressupostos filosóficos. O primeiro diz respeito ao entendimento do homem como um ser histórico-social que age na natureza, adaptando-a as suas necessidades e, nesse processo, transforma a si e a natureza. O segundo se refere à compreensão da realidade como um todo, síntese de múltiplas relações. A partir desses dois, surge um terceiro princípio, de natureza epistemológica, “[...] que consiste em compreender o conhecimento como uma produção do pensamento pela qual se apreende e se representam as relações que constituem e estruturam a realidade objetiva" (p. 16).

A autora propõe um desenho curricular baseado em quatro pontos. $\mathrm{O}$ primeiro seria a problematização de fenômenos, buscando a sua compreensão por meio de diferentes perspectivas, tais como, a tecnológica, histórica, ambiental, social, etc. "Isto significa elaborar questões sobre os fenômenos, fatos, situações e processos identificados como relevantes, com o intuito de desvelar sua essência - características, determinantes, fundamentos - que não se manifestam de imediato à nossa percepção e/ou experiência."(RAMOS, 2008,p. 20).

O segundo se relaciona com a busca pelo respaldo em teorias e conceitos fundamentais, para compreender os objetos estudados em suas diferentes perspectivas em que foi problematizado, valendo-se para isso da sua utilização em seus respectivos campos de ciência bem como de suas possibilidades no que concerne a disciplinaridade, 
através da verificação das suas relações dentro do seu próprio campo, e interdisciplinaridade, por meio analise de suas relações com outras áreas do saber (RAMOS, 2008).

$\mathrm{O}$ terceiro concerne à necessidade de os conhecimentos serem compreendidos como de formação geral e específica. Para isso, a sua base científica e sua apropriação tecnológica, social e cultural precisam ser analisadas (RAMOS, 2008). E o quarto, e último, segundo Ramos (2008), é que "A partir dessa localização e das múltiplas relações, organizar os componentes curriculares e as práticas pedagógicas, visando a corresponder, nas escolhas, nas relaçõese nas realizações, ao pressuposto da totalidade do real como síntese de múltiplasdeterminações." (p.21).

A elaboração de um currículo com esses aspectos basilares tem por objetivo possibilitar a percepção da realidade como resultado da interface de suas diferentes partes, ou seja, uma composição que vai além de sua aparência fenomênica. Dessa forma, o Currículo Integrado, ao contemplar de forma global o conhecimento, demonstra que os conteúdos não tem um fim em si mesmo e nem são subservientes a explicação de uma realidade inacabada. Mas, configuram-se como elementos essenciais da trajetória sócio-histórica do homem e que só fazem sentido, se entendidos de forma indissociável.

Ao propor o trato com os conhecimentos sobre as práticas corporais e a sua relação com os aspectos econômicos, políticos, históricos, culturais, dentre outros, a disciplina de Educação Física na Educação Profissional e Tecnológica, aproxima-se das sugestões de educação, consubstancializadas por meio da Escola Unitária, propostas por Gramsci. Para que isso de fato ocorra, o arranjo curricular, como vimos apresentado de forma complementar pelo Coletivo de Autores (1992), Araújo e Frigotto (2015) e Ramos (2008), deve viabilizar a integração dos saberes em suas distintas dimensões, além de abarcar princípios que considerem os conteúdos de reconhecida relevância e que favoreçam o diálogo com a bagagem da cultura corporal que o aluno já traz consigo. 
ISSN: $2594-4827$

\section{CONSIDERAÇÕES FINAIS}

Esse estudo teve por objetivo verificar de que forma a relação entre Escola Unitária, Educação física e Currículo Integrado pode se apresentar na Educação Profissional e Tecnológica. Para a consecução de uma proposta educacional na área de Educação Física, voltado para uma formação humana mais ampla, como a pretendida por Gramsci, a disciplina, que historicamente sempre esteve alinhada aos interesses das classes dominantes, deve redirecionar as suas ações, alicerçadas pela implantação de um Currículo Integrado, que ressalte a sua importância na Educação Profissional e Tecnológica.

A vivência regular da disciplina de Educação Física, na Educação Profissional e Tecnológica, ao passo em que busca colaborar no processo de formação integral do homem concorre, igualmente, para o aumento do subsídio às propostas pedagógicas que visam a diminuir os efeitos negativos, que o modo de produção capitalista, impõe sobre o trabalho. Essas contribuições são percebidas tanto pela ação de promover a sociabilização dos alunos no ambiente em que estão inseridos, quanto por atuar na sensibilização do "corpo trabalhador" (SANTOS, 2007).

É importante ressaltarmos o cuidado que se deve ter com a elaboração da proposta, seja no que diz respeito a Educação Físíca seja referente ao Currículo Integrado, para que estejam voltados para a formação humana de referência gramsciana. Propostas de cunho liberal, como a pedagogia das competências, também buscam a integração dos seus conhecimentos no curriculo e uma diversidade de conteúdos no trato com a Educação Físíca. Para estar calcada nas ideias de Gramsci, elas precisam estar visando a transformação social.

Assim, buscamospor meio desse estudo, apresentar os limites e possibilidadesda relação entre um componente curricular, o eixo curricular que lhe dá sustentação e uma categoria importante na Educação Profissional e Tecnológica, no caso a Escola Unitária. Queremos enfatizar que, acima de tudo, a viablidade de se efetivar uma proposta, que articule três pontos fundamentais do espaço educacional, como essa aqui analisada, é a sua busca pela transformação da realidade e, para tanto, deve ter sob o seu horizonte uma sociedade que vai além do capital. 
ISSN: $2594-4827$

\section{AGRADECIMENTOS}

Agradecemos ao IFRO, por meio do Programa de Incentivo à Qualificação (PIQ), pelo apoio na realização desse trabalho.

\section{REFERÊNCIAS}

ANVERSA, A. L. B; SOUZA, V. F. M. Educação em Gramsci: aproximações com o campo da educação física. Práxis Educacional (Online), v. 12, p. 153-174, 2016.

ARAUJO, R. M. L.; FRIGOTTO, G. Práticas Pedagógicas e Ensino Integrado. Revista Educação em Questão (Online), v. 52, p. 61-80, 2015.

BRASIL. Secretaria de Educação Fundamental. Parâmetros curriculares nacionais: Educação física / Secretaria de Educação Fundamental. Brasília: MEC/SEF, 1997.

COLETIVO DE AUTORES. Metodologia do ensino de educação física. 2. ed. rev. São Paulo: Cortez, 2012.

GIL, Antonio. C. Como elaborar projetos de pesquisa. 4. ed. São Paulo: Atlas, 2002. GRAMSCI, A. Cadernos do Cárcere. Vol 2. Rio de Janeiro: Civilização Brasileira, 2000.

RAMOS, M. N. Concepção do ensino médio integrado. 2008. Disponível em:<https://tecnicadmiwj.files.wordpress.com/2008/09/texto-concepcao-do-ensinomedio-integrado-marise-ramos1.pdf $>$. Acesso em: 04 de set. 2018.

RIBEIRO, E. C. S. ; SOBRAL, K. M.. ; JATAI, R. I. P. . Omnilateralidade, Politecnia, Escola Unitária e Educação Tecnológica: uma análise marxista. In: JORNADA INTERNACIONAL DE ESTUDOS E PESQUISAS EM ANTONIO GRAMSCI, 1., 2016, Fortaleza, Ceará. Anais... Fortaleza: UFCE, 2016, p.1-11.

SANTOS, J. O. dos. Educação Física e formação do trabalhador. Trabalho Necessário, Rio de Janeiro, ano 5, v.5, p.1-12, 2007. 